\title{
The effect of winter diet on the weight gain and body condition score of weanling dairy replacement heifers
}

E Kennedy, R Sayers, J.P. Murphy, S Fitzgerald, F Buckley

Dairy Production Research Centre, Teagasc Moorepark, Fermoy, Co. Cork, Ireland

Email: emer.kennedy@teagasc.ie

Introduction Heifers should be managed to achieve $55 \%$ to $60 \%$ of mature bodyweight (BW) at mating start date (Patterson et al., 1992). Ensuring the optimum development of replacement heifers is critical and needs to be accomplished at low cost without sacrificing performance. The feed costs of kale are over 30\% less than grass silage. Yet, feed and labour costs associated with kale increase when the recommendation of offering grass silage with kale is adhered to, thus a $100 \%$ kale diet would be attractive. The objective of this study was to investigate four contrasting winter feeding regimes on heifer BW gain and body condition score (BCS).

Materials and methods One hundred and twenty spring born weanling replacement dairy heifer calves were balanced on the basis of breed (Holstein Friesian; 87\% of herd, Montbelliarde $\times$ Holstein; 13\% of herd), age (282 \pm 16.3 days), bodyweight $(\mathrm{BW} ; 214 \pm 22.8 \mathrm{~kg}$ ) and body condition score (BCS; $2.94 \pm 0.309)$ in a randomised block design. They were then randomly assigned to one of four winter feeding treatments from 17 November 2008 to 10 February 2009 (85 days). The four feeding treatments were: i) indoors offered ad libitum high quality grass silage (HQS); ii) indoors offered ad libitum poor quality grass silage (PQS); iii) outdoors offered $70 \%$ kale and $30 \%$ grass silage (70K); iv) outdoors offered $100 \%$ kale $(100 \mathrm{~K})$. The high quality grass silage offered was $>70 \%$ DMD (dry matter digestibility) while the poor quality grass silage was $<65 \%$ DMD. The forage kale was grazed in situ. The $70 \mathrm{~K}$ animals were offered grass silage bales $>65 \%$ DMD. Prior to the commencement of the experiment all animals received one Tracesure ${ }^{\circledR}$ I bolus to provide iodine, selenium and cobalt supplementation. The $100 \mathrm{~K}$ treatment animals were offered straw for the first week of the study to adjust them to the $100 \%$ kale diet - no further fibre source was offered after the first week. All animals were offered fresh feed daily; the indoor animals grass silage refusals were removed daily, the outdoor animals were offered a fresh allocation of kale each morning by moving a temporary electric fence. All treatments were grouped individually. During the experimental period all animals were weighed weekly and condition scored every three weeks. All animals were turned out to pasture on 10 February and offered ad libitum grazed grass. All animals were then weighed weekly to the start of the breeding season (15 April) and monthly thereafter, while BCS was recorded monthly from turnout. All data were analysed using PROC MIXED in SAS. Animal was used as the experimental unit. Pre-experimental values were used as a covariate in the model. The data are reported in three periods, PI: the 85 day experimental period, PII: the period of time from turnout to the start of the breeding season and PIII: from after the commencement of the breeding season to 15 September 2009.

Results The DMD of the HQS was $72( \pm 3.0) \%$ and the dry matter (DM) was $22.2( \pm 1.32) \%$. The DMD and DM of the PQS were $60( \pm 1.6) \%$ and $26.1( \pm 2.36) \%$, respectively. The estimated Unité Fourragère Lait (UFL) value of the kale offered was $1.02 \mathrm{UFL} / \mathrm{kg}$ DM and was $0.78 \mathrm{UFL} / \mathrm{kg}$ DM for the HQS and $0.75 \mathrm{UFL} / \mathrm{kg}$ DM for the PQS. During PI the BW gain of the $70 \mathrm{~K}$ treatment was significantly greater $(\mathrm{P}<0.001)$ than all other three treatments $(0.26 \mathrm{~kg} / \mathrm{day})$. During PII BW gain for the $100 \mathrm{~K}$ treatment was greater $(+0.29 ; \mathrm{P}<0.001)$ than all other treatments $(0.85 \mathrm{~kg} / \mathrm{day})$. There was no difference in BW gain during PIII $(0.93 \mathrm{~kg}$ /day). During PI the BCS of the HQS, PQS and $100 \mathrm{~K}$ animals did not differ significantly (2.85) however the BCS of the HQS and PQS animals was less $(\mathrm{P}<0.001)$ than the $70 \mathrm{~K}$ animals. There was no difference in BCS between the $70 \mathrm{~K}$ and $100 \mathrm{~K}$ treatments (2.93). All animals had similar BCS in PII (3.08) and PIII (3.24). The lower weight gain of the $100 \mathrm{~K}$ treatment relative to the $70 \mathrm{~K}$ treatment is partly attributable to gut fill, especially given that there was no difference in BCS at the end of PI and the high BW gain in PII. There was no difference in total BW accretion between the $70 \mathrm{~K}$ and $100 \mathrm{~K}(237 \mathrm{~kg})$ but it was higher $(\mathrm{P}<0.001)$ then the HQS and PQS $(220 \mathrm{~kg})$.

Table 1 Effects of winter feeding treatment on bodyweight (BW) and body condition score (BCS)

\begin{tabular}{l|llllll}
\hline \hline & HQS & PQS & $70 \mathrm{~K}$ & $100 \mathrm{~K}$ & SED & Sig \\
\hline BW gain/day PI (kg/day) & $0.28^{\mathrm{a}}$ & $0.27^{\mathrm{a}}$ & $0.52^{\mathrm{b}}$ & $0.24^{\mathrm{a}}$ & 0.133 & 0.001 \\
BW gain/day PII (kg/day) & $0.84^{\mathrm{a}}$ & $0.89^{\mathrm{a}}$ & $0.82^{\mathrm{a}}$ & $1.14^{\mathrm{b}}$ & 0.153 & 0.001 \\
BW gain/day PIII & 0.94 & 0.89 & 0.93 & 0.94 & 0.150 & 0.598 \\
(kg/day) & & & & & \\
Average BCS PI & $2.84^{\mathrm{a}}$ & $2.83^{\mathrm{a}}$ & $2.97^{\mathrm{b}}$ & $2.89^{\mathrm{ab}}$ & 0.1464 & 0.001 \\
Average BCS PII & 3.12 & 3.06 & 3.09 & 3.05 & 0.1973 & 0.610 \\
Average BCS PIII & 3.23 & 3.18 & 3.26 & 3.28 & 0.1476 & 0.076 \\
\hline \hline
\end{tabular}

$\mathrm{S}{ }^{\mathrm{abc}}$ values in the same row not sharing a common superscript are significantly different

\section{Conclusion}

The results from this study indicate that higher BW gains can be achieved during the winter period by offering a kale based diet which resulted in higher BW at mating start date. Furthermore, 100K animals had high BW gain in PII suggesting that it is possible to offer $100 \%$ kale, with no additional fibre source, over the winter period.

\section{References}

Patterson, D. J., Perry, R. C., Kiracofe, G. H., Bellows, R. A., Staigmiller, R. B., Corah, L. R. 1992. Journal of Animal Science $70,4018-4035$ 